Research Article

\title{
Research on Multiobjective Location of Urban Emergency Logistics under Major Emergencies
}

\author{
Hongchun Wang and Xinying Ma $\mathbb{D}$ \\ School of Urban Economics and Management, Beijing University of Civil Engineering and Architecture, Beijing 100044, China \\ Correspondence should be addressed to Xinying Ma; mxy63127@163.com
}

Received 16 February 2021; Revised 14 March 2021; Accepted 26 April 2021; Published 6 May 2021

Academic Editor: Neale R. Smith

Copyright (C) 2021 Hongchun Wang and Xinying Ma. This is an open access article distributed under the Creative Commons Attribution License, which permits unrestricted use, distribution, and reproduction in any medium, provided the original work is properly cited.

\begin{abstract}
After the outbreak of major emergencies, the scheduling of emergency supplies is the key to the emergency rescue work, and the establishment of appropriate emergency logistics centers plays a crucial supporting role. In order to deal with the problem of emergency facility location and material distribution in urban emergency logistics system, this paper establishes a dual objective mixed integer nonlinear programming (MINLP) model with the objective of minimizing the emergency rescue time and maximizing the satisfaction rate of emergency material demand, designs a genetic algorithm to solve the emergency logistics location and allocation model, and obtains the Pareto optimal solution set of the model. Finally, a case study of COVID-19 epidemic in Beijing-Tianjin-Hebei region was carried out to verify the feasibility and effectiveness of the model and algorithm in the actual application, which can provide reference and suggestions for the location and material distribution of urban emergency logistics centers.
\end{abstract}

\section{Introduction}

Urban emergency logistics is a kind of logistics activity, where the cities urgently guarantee the logistics demand to reduce their own losses under the influence of sudden natural disasters, major public health events, public security events, large-scale group events, and other emergencies. The emergency logistics centers are important nodes in the emergency logistics network. In order to meet the needs of emergency material demand in major emergencies, the emergency logistics centers will play a role as a place to collect and store rescue materials and carry out a series of work such as transportation, circulation, scheduling, and distribution of materials. In recent years, all kinds of major emergencies have occurred from time to time in many countries and regions in the world, from the Tangshan earthquake to the Wenchuan earthquake, from SARS to avian influenza and now to the global COVID-19 epidemic, and from the "911" incident to the frequent mine accidents in recent years. The outbreak of major emergencies not only pose a serious threat to people's life safety but also bring inconveniences to people's production, life, and commodity circulation, which has a strong impact on social and economic development.

Therefore, when major emergencies break out, how to carry out emergency rescue for the affected people and make them get rapid treatment has become a task of top priority. In this process, ensuring the rapid and effective supply of emergency relief materials is the fundamental guarantee. How to reasonably allocate emergency resources and farthest minimize the losses caused by the disaster is a key problem worthy of consideration in emergency logistics. In the emergency rescue work, the establishment of stable emergency logistics centers will play an indispensable supporting role.

Under the background of the frequent occurrence of various major emergencies in the world, many scholars at home and abroad are devoted to the research of emergency logistics problems such as emergency facility location, material distribution, and emergency logistics network optimization. For example, scholar Ekici combines the epidemic transmission model with facility location and 
material distribution network, establishes a location optimization model for food distribution, and designs the heuristic algorithm in order to solve the practical problems of Georgia [1]. Barzinpour and Esmaeili proposed a new multiobjective mixed integer linear programming model, which took the humanitarian and cost into account, and allocated people affected by the disaster in the city to the local emergency management facilities [2]. Tuzkaya et al. considered many factors that affect the convenience of emergency logistics center and combined DEMATEL and ANP method to determine the locations of emergency logistics centers among the alternative sites [3]. Liu et al. proposed a new emergency service level function considering the proportion of emergency material demand satisfaction degree and the total cost of emergency rescue, established an emergency logistics network optimization model based on service level in an outburst of epidemic, and obtained the near-optimal solution of the model with the genetic algorithm [4]. As for the problem of emergency logistics center location and material allocation, the mathematical programming method is most widely used in large numbers of existing emergency logistics modeling papers. Many years ago, experts and scholars mostly used the singleobjective modeling method to solve this kind of problem. For example, in order to solve the problem of how to optimize the allocation of resources in the disaster area at the early search and rescue stage after the strong earthquake, the scholars Fiedrich et al. took the minimum number of deaths as an objective to establish a dynamic optimization model and gave the solution method based on vehicle flow and commodity flow [5]. Considering the distribution of emergency supplies and the transportation of the wounded under natural disasters, Yi and Özdamar proposed a mixed integer multicommodity network flow model for the problem of how to establish temporary treatment points and plan emergency vehicle paths in disaster areas, aiming at minimizing service delay, and adopted the routing algorithm to solve it [6]. In recent years, the multiobjective modeling method is more widely used in complex emergency logistics center location and allocation problems. For example, considering the efficiency and fairness of emergency rescue facilities, scholars Chen and You established a multiobjective decision-making model by integrating the three commonly used location models of the maximum coverage model, p-center model, and p-median model and further discussed solving strategies and methods with specific examples [7]. Wang et al. set the shortest average vehicle transportation time and the minimum total cost as the objective to establish a multivehicle open location-routing model and used the genetic algorithm to obtain the Pareto optimal solution set [8]. Chen et al. established a multicommodity, multimodal transport, and multistage emergency logistics location allocation model under uncertain material supply and demand with the objective of minimizing insufficient demand, total time, and total cost and effectively found out the Pareto optimal solution set of the model with the epsilon constraint method [9]. Zheng et al. established a bilevel programming dynamic model of two-level disaster relief network after the earthquake and designed a hybrid genetic algorithm to solve the model [10]. Zheng et al. established a multiobjective 0-1 integer location model and evaluation model with the goal of maximum coverage rate and minimum total time cost, solved the model by using depth-first search and fuzzy neural network, and compared the multiobjective model with the single-objective model to verify the good performance of the model and algorithm [11].

Nowadays, the occurrence of emergencies is more and more diversified, and the impact of major emergencies has exceeded people's expectations. Because of its burstiness, unpredictability, wide range of impact, and strong destructiveness, decision makers must complete the dispatch of emergency materials in the shortest time and carry out emergency rescue, material support, and protection of secondary emergencies. Through literature review, it can be seen that in the existing literatures, the research methods of emergency logistics center location and material allocation are constantly optimized, and the models are constantly innovated. Most of the single-objective location models are constructed with the factors of cost, distance, coverage rate, demand satisfaction rate, and so on, or the multiobjective location models are constructed by arranging and combining the above factors, but there are not many articles taking the combination of time and demand satisfaction rate as the multiobjective to construct model. The location of emergency logistics facilities is complex, and the decision makers need to consider a variety of factors. If only one factor is considered without the constraint of another factor, the solution obtained will tend to be extreme. On this condition, the location is usually based on two or more mutually restricted objectives. Therefore, the multiobjective programming model is chosen to solve this problem. And when modeling in the complex situation, the variables include discrete variables and continuous variables and the objective function is nonlinear, so the multiobjective mixed integer nonlinear programming model is selected to solve this problem. In this paper, considering that in the context of some major emergencies (such as SARS), the country will carry out emergency rescue regardless of cost, so the multiobjective mixed integer nonlinear programming model is established with the goal of the minimum demand satisfaction rate and the shortest emergency rescue time. In the normal logistics location model, cost is an important factor. However, in this paper, under the background of major emergencies, especially the major public health events such as SARS and COVID-19, because the delay of emergency material transportation will cause more serious consequences, the cost factor is weakened and first considers the emergency rescue time to maximize the rescue efficiency. In addition, the demand satisfaction rate is not an important factor in the normal logistics location model. If the supply of demand point is far less than the demand, it can be solved by redistribution. While in the emergency location model, considering the urgency of demand, the demand of the demand point should be met as much as possible in the primary distribution. Therefore, at the same time we meet the need of the shortest emergency rescue time and the need of highest satisfaction rate should also be met. Taking the COVID-19 epidemic in Beijing-Tianjin-Hebei region as an 
example, appropriate number of emergency logistics centers are established within the scope of Beijing-Tianjin-Hebei region and emergency materials allocation is carried out during the outbreak of the epidemic in order to verify the feasibility of the emergency logistics center location allocation model and algorithm, and suggestions are provided for the allocation of emergency materials in each region during the outbreak of major emergencies.

\section{Urban Emergency Logistics Center Location Model}

2.1. Problem Description. After the outbreak of large-scale major emergencies, a number of emergency logistics centers need to be established rapidly in a region. The relevant departments need to allocate a large number of emergency materials from the material supply points to the emergency logistics centers and then distribute them to the disaster areas, namely, the material demand points. Therefore, a three-level emergency logistics network including material supply points, emergency logistics centers, and material demand points needs to be established, as shown in Figure 1. Under the constraints of limited time, space, and resources and considering the material demand of the emergency demand points, we need to solve how to reasonably locate the emergency logistics centers and allocate materials with the two objectives of minimizing the emergency rescue time and maximizing the satisfaction rate of the emergency material demand. Specific issues include the following:

(1) How many emergency logistics centers need to be set in the middle of the transportation of emergency materials from the material supply points to the material demand points

(2) Where the emergency logistics centers are set up and to which material demand points it is responsible for transporting

(3) What is the satisfaction rate of emergency material demand at each material demand point

(4) What is the optimal emergency rescue time from material supply points to material demand points

In order to better construct the model, the following assumptions are put forward:

(1) Not considering the differences of transportation modes of rescue materials, that is, simplifying the types and transportation modes of emergency rescue materials, only considering a single transportation mode (usually road transportation), and meeting the accessibility of vehicle transportation between network nodes;

(2) The material demand of each material demand point does not exceed the material storage of the corresponding emergency logistics center and can jointly be transported by vehicles;

(3) All kinds of emergency materials meet the compatibility of transportation; that is, the situation that

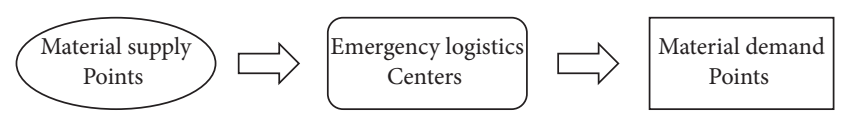

FIgURE 1: Three-level emergency logistics network.

different emergency materials cannot be transported at the same time is not considered;

(4) Regardless of the working time limit and vehicle capacity limit of transport vehicles, it is assumed that each material supply point and emergency logistics center has a sufficient number of transport vehicles and sufficient vehicle carrying capacity;

(5) In order to shorten the time of emergency rescue, the emergency logistics centers distribute the emergency materials to the corresponding material demand points as soon as they receive the emergency materials; that is, the turnover time of the emergency materials in the emergency logistics centers is not considered.

2.2. Parameter Setting. Table 1 describes the parameter setting.

\subsection{Model Establishment}

2.3.1. Multiobjective Model. Based on the above parameters, the location allocation model of urban emergency logistics center is established as follows:

$$
\begin{aligned}
& \min Z_{1}=\sum_{i=1}^{I} \sum_{j=1}^{J} t_{u i} W_{u i}+t_{i j} W_{i j}, \\
& \max Z_{2}=\sum_{j=1}^{J} w_{j} h_{j}, \\
& \text { s.t. } h_{j}=\frac{\sum_{i=1}^{I} W_{i j} m_{i j}}{d_{j}}, \\
& s_{u i}=\sqrt{\left(x_{i}-x_{u}\right)^{2}+\left(y_{i}-y_{u}\right)^{2}}, \\
& s_{i j}=\sqrt{\left(x_{j}-x_{i}\right)^{2}+\left(y_{j}-y_{i}\right)^{2},} \\
& t_{u i}=\frac{s_{u i}}{v_{u i}}, \\
& t_{i j}=\frac{s_{i j}}{v_{i j}}, \\
& c_{i}=\frac{\sum_{j=1}^{J} m_{i j}}{\sum_{i=1}^{I} \sum_{j=1}^{J} m_{i j}}, \quad \forall i \in I,
\end{aligned}
$$


TABle 1: Parameter setting.

\begin{tabular}{|c|c|}
\hline & Implication \\
\hline \multicolumn{2}{|l|}{ Set } \\
\hline$U$ & Set of emergency material supply point $u, u=1,2,3, \ldots, U$ \\
\hline I & Set of emergency logistics center $i, i=1,2,3, \ldots, I$ \\
\hline$J$ & Set of material demand point $j, j=1,2,3, \ldots, J$ \\
\hline \multicolumn{2}{|r|}{ - } \\
\hline$w_{j}$ & $\begin{array}{l}\text { Weight of material demand point } j \text {, namely, the proportion of the number of people in material demand point } j \text { to the } \\
\text { total number of people in all material demand points }\end{array}$ \\
\hline$a_{u}$ & Supply capacity of emergency material supply point $u$ \\
\hline$\left(x_{u}, y_{u}\right)$ & Position coordinate of emergency supply point $u$ \\
\hline$\left(x_{i}, y_{i}\right)$ & Position coordinate of emergency logistics center $i$ \\
\hline$\left(x_{j}, y_{j}\right)$ & Position coordinate of emergency demand point $j$ \\
\hline$r$ & Maximum distribution radius of emergency logistics centers \\
\hline$s_{u i}$ & Distance between material supply point $u$ and emergency logistics center $i$ \\
\hline$s_{i j}$ & Distance between emergency logistics center $i$ and material demand point $j$ \\
\hline$v_{u i}$ & Transportation speed of materials from material supply point $u$ to emergency logistics center $i$ \\
\hline$v_{i j}$ & Transportation speed of materials from emergency logistics center $i$ to material demand point $j$ \\
\hline$t_{u i}$ & Transportation time of emergency materials from material supply point $u$ to emergency logistics center $i$ \\
\hline$t_{i j}$ & Transportation time of emergency materials from emergency logistics center $i$ to material demand point $j$ \\
\hline$c_{i}$ & Relative size of emergency logistics center $i$ \\
\hline$d_{j}$ & Material demand of emergency demand point $j$ \\
\hline$h_{j}^{\prime}$ & Material demand satisfaction rate of emergency demand point $j$ \\
\hline$z_{i}$ & Material storage capacity of emergency logistics center $i$ \\
\hline$m_{u i}$ & Quantity of emergency materials transported from material supply point $u$ to emergency logistics center $i$ \\
\hline$m_{i j}$ & Quantity of emergency materials transported from emergency logistics center $i$ to material demand point $j$ \\
\hline \multicolumn{2}{|c|}{ Decision variable } \\
\hline$X_{i} \in\{0,1\}$ & $\begin{array}{l}\text { Whether to locate at emergency logistics center } i, x_{i}=1 \text { means to establish an emergency logistics center at point } i \text {, } \\
\qquad X_{i}=0 \text { means that the emergency logistics center will not be established at point } i\end{array}$ \\
\hline$W_{u i} \in\{0,1\}$ & Whether to transport the materials from material supply point $u$ to emergency logistics center $i$ \\
\hline$W_{i j} \in\{0,1\}$ & Whether to transport the materials from emergency logistics center $i$ to material demand point $j$ \\
\hline
\end{tabular}

$$
\begin{gathered}
\sum_{i=1}^{I} W_{i j}=1, \quad \forall j \in J, \\
\sum_{i=1}^{I} W_{i j} m_{i j} \leq d_{j}, \quad \forall j \in J, \\
\sum_{u=1}^{U} X_{i} m_{u i}=\sum_{j=1}^{J} W_{i j} m_{i j}, \quad \forall i \in I, \\
\sum_{i=1}^{I} \sum_{j=1}^{J} W_{i j} m_{i j}=\min \left\{\sum_{u=1}^{U} a_{u}, \sum_{j=1}^{J} d_{j}\right\} \\
W_{i j} \leq X_{i}, \quad \forall i \in I, j \in J \\
\sum_{i=1}^{I} X_{i} \leq I, \quad \\
\sum_{i=1}^{I} m_{u i} \leq a_{u}, \quad \forall u \in U, \\
s_{i j} \leq r, \quad \forall i \in I, j \in J
\end{gathered}
$$

$$
\begin{aligned}
X_{i}, W_{u i}, W_{i j} \in\{0,1\}, \quad \forall i \in I, j \in J, \\
m_{u i}, m_{i j} \in R^{+}, \quad \forall u \in U, \forall i \in I, j \in J .
\end{aligned}
$$

In the above urban emergency logistics center location allocation model, the objective function (1) is to minimize the emergency rescue time and the objective function (2) is to maximize the material demand satisfaction rate. Formula (3) is the calculation method of demand satisfaction rate. Formula (4) is the Euclidean distance from material supply point $u$ to emergency logistics center $i$, and formula (5) is the Euclidean distance from emergency logistics center $i$ to material demand point $j$ (the distance between material supply points and emergency logistics centers and the distance between emergency logistics centers and material demand points are expressed by Euclidean distance). Formulas (6) and (7) are the calculation methods of emergency rescue time. Formula (8) is the calculation method of the relative size of emergency logistics center $i$. Constraint (9) indicates that the emergency materials of each material demand point are only provided by one emergency logistics center. Constraint (10) indicates that the quantity of emergency materials provided to each material demand point does not exceed the demand quantity of the demand point. Constraint (11) indicates that the emergency materials received by each emergency logistics center are equal to those sent by the emergency logistics center. Constraint (12) 
indicates that if the supply capacity of the material supply point is smaller than the demand of the material demand point, all emergency materials shall be transported to the material demand point; otherwise, the emergency rescue materials shall be distributed according to the demand of the emergency demand points. Constraint (13) indicates that only the established emergency logistics centers can distribute emergency materials to the material demand points. Constraint (14) indicates that the number of emergency logistics centers does not exceed the original upper limit. Constraint (15) indicates that the quantity of emergency materials provided by each material supply point does not exceed its supply capacity. Constraint (16) indicates that the distances between material demand points and emergency logistics centers do not exceed its maximum distribution radius. Constraints (17) and (18) represent the types of decision variables and several state variables. Due to the properties of variables and objective functions, this is a $0-1$ mixed integer nonlinear programming model.

The following are further explanations of some of the above formulas:

(1) In the three-level emergency logistics network established in this paper, the material supply points, emergency logistics centers, and material demand points are all nodes in the network, and the location of nodes is expressed by their geographical coordinates. Therefore, the distance between every two city nodes in formula (4) is expressed by European distance. If the shortest highway mileages in the actual situation are used, it is difficult to combine the geographical coordinates of the cities with them. The final solution of the location model constructed in this paper is the coordinates of the emergency logistics centers found out, so we need to take the Euclidean distance as the constraint condition.

(2) $c_{i}$ can not directly affect the objective function but it is related to the parameter $m_{i j}$ in the objective function, and its calculation method is shown in formula (8). When the optimal solution of the objective function is obtained, the proportion of the material transportation volume of an emergency logistics center $\sum_{j=1}^{J} m_{i j}$ in the total material transportation volume of all emergency logistics centers $\sum_{i=1}^{I} \sum_{j=1}^{J} m_{i j}$ can be obtained, as well as the relative scale of an emergency logistics center $c_{i}$.

(3) The scope of urban emergency logistics center location studied in this paper is in a region. The transportation of materials from the emergency logistics centers to the material demand points in a region usually uses road transportation. When major emergencies occur in the region, it is necessary to quickly mobilize emergency materials around the region to save the time of material transportation. Road transportation is also the main way to transport materials from the adjoining areas of the region to the emergency logistics centers in the region, so the transportation speed in formulas (6) and (7) is consistent.
2.3.2. Model Transformation. Because the objective function $Z_{1}$ is the minimum value and the objective function $Z_{2}$ is the maximum value, we take the opposite number of the objective function $Z_{2}$ and add it to the objective function $Z_{1}$. The problem is transformed into a single-objective problem. Then, the location allocation model of urban emergency logistics center under major emergencies can be transformed into the following expression:

$$
\min Z_{1}=\sum_{i=1}^{I} \sum_{j=1}^{J} t_{u i} W_{u i}+t_{i j} W_{i j}-\sum_{j=1}^{J} w_{j} h_{j} .
$$

In addition, in the case of only considering a single mode of transportation (road transportation), assuming that the transportation speed of transport vehicles is same and constant, the problem of minimizing the emergency rescue time can be transformed into the problem of minimizing the sum of the distances from the material supply points to the material demand points. The expression is as follows:

$$
\min Z_{1}=\sum_{i=1}^{I} \sum_{j=1}^{J} s_{u i} W_{u i}+s_{i j} W_{i j}-\sum_{j=1}^{J} w_{j} h_{j}
$$

\section{Model Solution}

In this paper, the urban emergency logistics center location allocation model under major emergencies is a $0-1$ mixed integer nonlinear programming model, which involves a large scale of data, including the population data, location data, demand data of each material demand point, and material reserve data of material supply points. Then, the number and locations of emergency logistics centers are unknown, which means the problem to be solved is a NPhard problem. After the multiobjective mixed integer nonlinear programming model is established, the computational cost of solving the model is high. As there are many variables and constraints with complex forms, the model is usually transformed into a single-objective programming model and solved by the heuristic algorithm. If the accurate algorithm is used to solve the problem, it will increase the difficulty and cost more time. In the context of major emergency rescue, it is necessary to meet the timeliness requirements and find the near-optimal solution of the model in the shortest time. Therefore, this paper uses the genetic algorithm to solve the model according to the characteristics of the model. In addition, when using the genetic algorithm to solve the model, the unknown variables need to be put into the chromosome codes, which require the real data of variables except those serve as chromosome codes can be collected in the example analysis. And the flow chart of the genetic algorithm is shown in Figure 2. The specific algorithm steps are as follows:

Step 1. Initialize parameters: Set the population size "sizepop," the iterative times "MAXGEN," the crossover probability " $p_{c}$," and mutation probability " $p_{m}$. "

Step 2. Chromosome coding: In the genetic algorithm, a chromosome corresponds to a solution of the model. 


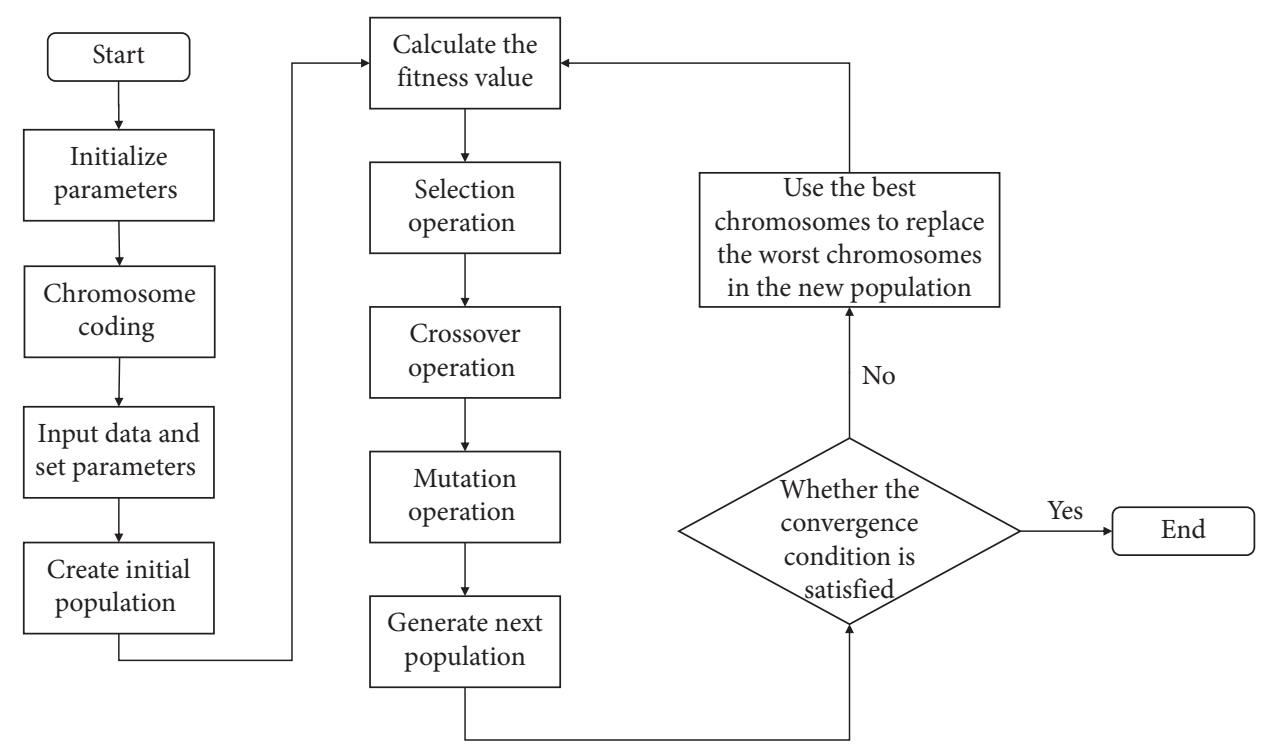

FIGURE 2: Flow chart of the genetic algorithm.

The variables to be solved in the constructed model of this paper include integer variables and noninteger variables, and the data structure is complex. So, the real coding is used as follows:

$$
\left[\begin{array}{llllllllll}
x_{i} & y_{i} & m_{1 i} & m_{2 i} & \cdots & m_{U i} & m_{i 1} & m_{i 2} & \cdots & m_{i J}
\end{array}\right] \text {. }
$$

The number of rows of chromosome corresponds to the number of emergency logistics centers, and the first two columns of chromosome are the locations of emergency logistics center " $\left(x_{i}, y_{i}\right)$." The next $U$ columns are the quantities of emergency materials " $m_{u i}$ " from the material supply points to the emergency logistics centers, and the $J$ columns behind are the emergency material quantity " $m_{i j}$ " distributed by the emergency logistics centers to the material demand points. For each chromosome, when the number of emergency logistics centers is given, their positions " $\left(x_{i}, y_{i}\right)$ " are generated randomly. When the number and locations of emergency logistics centers are determined, the following $U+J$ columns are the optimal solutions of emergency material scheduling on each route under the given situations.

Step 3. Input data and set parameters: Input all relevant parameter data involved in the model.

Step 4. Create the initial population: The initial populations satisfying chromosome coding rules are generated randomly.

Step 5. Calculate the fitness value. Because the objective function is to seek the minimum value, in order to maximize the fitness function, we need to take the reciprocal of the objective function to get the fitness function and calculate the fitness value of each chromosome according to the fitness function.

Step 6. Selection operation: Roulette wheel selection was used.
Step 7. Crossover operation: Chromosomes include the coordinates of emergency logistics centers and the quantities of emergency supplies. Therefore, chromosome crossover cannot be carried out directly, but chromosomes of site selection and material allocation are crossed separately. Site selection chromosomes use two-point crossover, while material allocation chromosomes use arithmetic crossover.

Step 8. Mutation operation: The site selection chromosomes and material allocation chromosomes are also mutated separately. The site selection chromosomes use the exchange mutation, and the material allocation chromosomes use the random neighborhood mutation.

Step 9. Generate the next population: The elitism strategy is applied to the remaining chromosomes to obtain the next generation population.

Step 10. Judge whether the convergence condition is satisfied: When the iterative times reach the preset value, judge whether the maximum fitness value and the average fitness value tend to be stable and meet the expectation; if yes, go to the next step; otherwise, replace the chromosomes which have the lowest fitness value in the new population with the obtained best chromosomes and return to step 5.

Step 11. Finish the calculation and output the result. The optimal chromosomes and fitness value are recorded.

\section{Example Analysis}

In this paper, we take the first four stages (from the discovery of unexplained pneumonia cases in Wuhan, Hubei Province, on December 27, 2019, to the normalization of national epidemic prevention and control on April 29, 2020 - according to <Fighting Covid-19 China in Action>) 
of COVID-19 epidemic in Beijing-Tianjin-Hebei region as an example to verify the effectiveness of the model and algorithm in the actual major emergencies and take 13 prefecture level cities in Beijing-Tianjin-Hebei region as 13 material demand points $j(j=1,2,3, \ldots, 13)$. The demand of material demand points is determined by the total number of patients infected with COVID-19 in the period. Suppose that each patient has 100 units of emergency medical drugs from diagnosis to cure or death, and the specific parameters are shown in Table 2. In addition, Binzhou of Shandong Province and Dalian of Liaoning Province, which are the nearest production bases of an antiviral drug manufacturer from Beijing-Tianjin-Hebei region, are selected as two emergency material supply points $u(u=1,2)$. The geographical coordinates of the two cities are (37.22 and 118.02) and (38.55 and 121.36), and the supply capacities are 62000 and 42000 . We take 13 cities in the region as alternative emergency logistics centers and plan to select 4 cities out of the 13 cities to establish emergency logistics centers $i(i=1,2,3,4)$.

According to the 2019 national economic and social development statistical communique of Beijing, Tianjin, and Hebei Province, the number of permanent residents of 13 prefecture level cities in Beijing-Tianjin-Hebei region by the end of 2019 is obtained as follows: 21.536 million in Beijing, 15.6183 million in Tianjin, 10.3942 million in Shijiazhuang, 7.964 million in Tangshan, 3.1463 million in Qinhuangdao, 9.5497 million in Handan, 7.3952 million in Xingtai, 9.399 million in Baoding, 4.4233 million in Zhangjiakou, 3.5827 million in Chengde, 7.5443 million in Cangzhou, 4.795 million in Langfang, and 4.486 million in Hengshui.

4.1. Test Result. Input the set parameters into Matlab and solve the model. Run the algorithm for 20 times, and take the average value of 25.2223 as the approximate optimal solution of the objective function. At this time, the minimum value of the sum of the distances from the material supply points to the material demand points through the emergency logistics centers is 26.1557 , and the maximum value of the sum of the demand satisfaction rate of each material demand point is 0.9334 . Through 20 repeated calculations and statistical analysis of the calculation results, we can get that the average operation time of the algorithm is 93.454 seconds, and the standard deviation of the calculation results is 0.4156 . The results show that the calculation results of the genetic algorithm have a certain stability, and the reliability of the calculation results can be improved by repeated operations.

4.1.1. Demand Satisfaction. Because the total supply of emergency materials is less than the total demand, the total demand satisfaction rate is less than 1, the overall demand of Beijing-Tianjin-Hebei region is unsatisfied, and the total demand satisfaction rate is relatively high, slightly less than the ratio of material supply to demand of 0.9446 , which reflects the effectiveness of the emergency logistics center location model in material allocation, and the demand satisfaction of each material demand point is shown in Table 3. It can be seen from Table 3 that in the case of limited material supply, in order to meet the goals of the shortest emergency rescue time and the largest material demand satisfaction rate at the same time, the demand of each demand point is not met.

In addition, it is not difficult to see that the demand satisfaction rate of core cities (Beijing, Tianjin, and so on) is generally higher than that of edge cities (Zhangjiakou, Qinhuangdao, Chengde, and so on), and node cities (Beijing, Tianjin, Xingtai, and Tangshan) as emergency logistics centers have significantly higher demand satisfaction rate than other cities, and cities with higher population density (Beijing, Tianjin, Shijiazhuang, Tangshan, and so on) also have high demand satisfaction rate. Generally speaking, geographical location, traffic conditions, and population density are factors to measure the level of economic development; thus, it can be seen that the emergency materials demand of cities with higher level of economic development is easier to be met when major emergencies occur. According to objective function (2), the greater the weight of urban population is, the easier its demand to be met, and the smaller the urban material demand is, the easier its demand to be met. It can be found from Table 2 that Shijiazhuang, Handan, and Baoding have larger population weight when the material demand quantity is not very large. Through the solution of the objective function by the genetic algorithm, we can see from Table 3 that, under the constraint of objective function (1), Beijing, Tianjin, Tangshan, and Xingtai, where the emergency logistics centers are located, are among the top four in terms of demand satisfaction rate, followed by Shijiazhuang, Handan, and Baoding closely. Therefore, the algorithm has high reliability.

4.1.2. Location Allocation Result. The result shows that the optimal emergency logistics network is shown in Figure 3 when four emergency logistics centers are established in Beijing-Tianjin-Hebei region. The four emergency logistics centers are located in Beijing, Tianjin, Xingtai, and Tangshan. The geographical location and relative size of each emergency logistics center are shown in Table 4.

Based on this, the urban emergency logistics network in Beijing-Tianjin-Hebei region after the locations of emergency logistics centers is determined under the outbreak of epidemic and is drawn on the map of Beijing-Tianjin-Hebei region (as shown in Figure 4). From Figures 3 and 4, it can be seen that emergency logistics center 1 in Beijing undertakes the emergency materials supply of Beijing, Zhangjiakou, Baoding, and Langfang; emergency logistics center 2 in Tianjin is responsible for the emergency materials distribution of Tianjin and Cangzhou; emergency logistics center 3 in Xingtai distributes emergency materials to Xingtai, Shijiazhuang, Handan, and Hengshui; and emergency logistics center 4 in Tangshan provides emergency materials for Tangshan, Chengde, and Qinhuangdao (as shown in Table 5).

It can be seen from Table 4 that emergency logistics center 1 located in Beijing undertakes the larger material turnover $(63.23 \%)$ in the emergency logistics network, while emergency logistics centers 3 and 4 located in Xingtai and 
TABLE 2: Locations and demand of material demand points.

\begin{tabular}{lccc}
\hline Material demand point $j$ & Geographic coordinate $\left(x_{j}, y_{j}\right)$ & Weight $w_{j}$ & Material demand quantity $d_{j}$ \\
\hline Beijing & $(39.55,116.24)$ & 0.196 & 59300 \\
Tianjin & $(39.02,117.12)$ & 0.142 & 19000 \\
Shijiazhuang & $(38.02,114.30)$ & 0.095 & 2900 \\
Tangshan & $(39.36,118.11)$ & 0.072 & 5800 \\
Qinhuangdao & $(39.55,119.35)$ & 0.029 & 1000 \\
Handan & $(36.36,114.28)$ & 0.087 & 3200 \\
Xingtai & $(37.04,114.30)$ & 0.067 & 2300 \\
Baoding & $(38.51,115.30)$ & 0.086 & 3200 \\
Zhangjiakou & $(40.48,114.53)$ & 0.04 & 4100 \\
Chengde & $(40.59,117.57)$ & 0.033 & 700 \\
Cangzhou & $(38.18,116.52)$ & 0.069 & 4800 \\
Langfang & $(39.31,116.42)$ & 0.044 & 3000 \\
Hengshui & $(37.44,115.42)$ & 0.04 & 800 \\
\hline
\end{tabular}

TABLE 3: Demand satisfaction of material demand points.

\begin{tabular}{lccc}
\hline Material demand point & Material demand quantity & Material supply quantity & Demand satisfaction rate (\%) \\
\hline Beijing & 59300 & 56349 & 95.02 \\
Tianjin & 19000 & 18323 & 96.44 \\
Shijiazhuang & 2900 & 2702 & 93.17 \\
Tangshan & 5800 & 5428 & 93.59 \\
Qinhuangdao & 1000 & 907 & 90.7 \\
Handan & 3200 & 2959 & 92.47 \\
Xingtai & 2300 & 2174 & 94.52 \\
Baoding & 3200 & 2920 & 91.25 \\
Zhangjiakou & 4100 & 3730 & 90.98 \\
Chengde & 700 & 621 & 88.71 \\
Cangzhou & 4800 & 4399 & 91.65 \\
Langfang & 3000 & 2761 & 92.03 \\
Hengshui & 800 & 727 & 90.88 \\
\hline
\end{tabular}

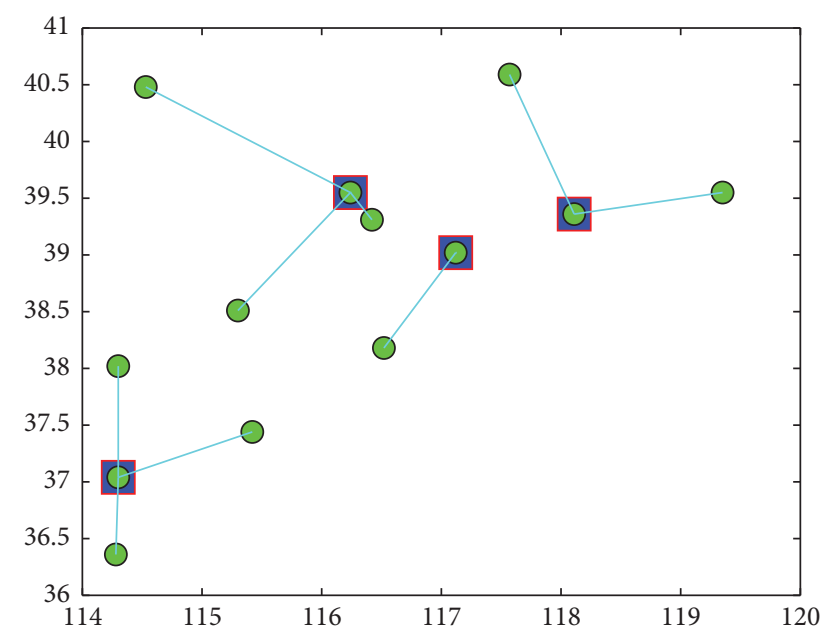

FIgURE 3: Locations and distribution of emergency logistics centers.

TABLE 4: Sites and relative size of emergency logistics centers.

\begin{tabular}{lccc}
\hline No. & Geographical coordinate & City & Relative size \\
\hline 1 & $(39.55,116.24)$ & Beijing & 0.6323 \\
2 & $(39.02,117.12)$ & Tianjin & 0.2185 \\
3 & $(37.04,114.30)$ & Xingtai & 0.0823 \\
4 & $(39.36,118.11)$ & Tangshan & 0.0669 \\
\hline
\end{tabular}




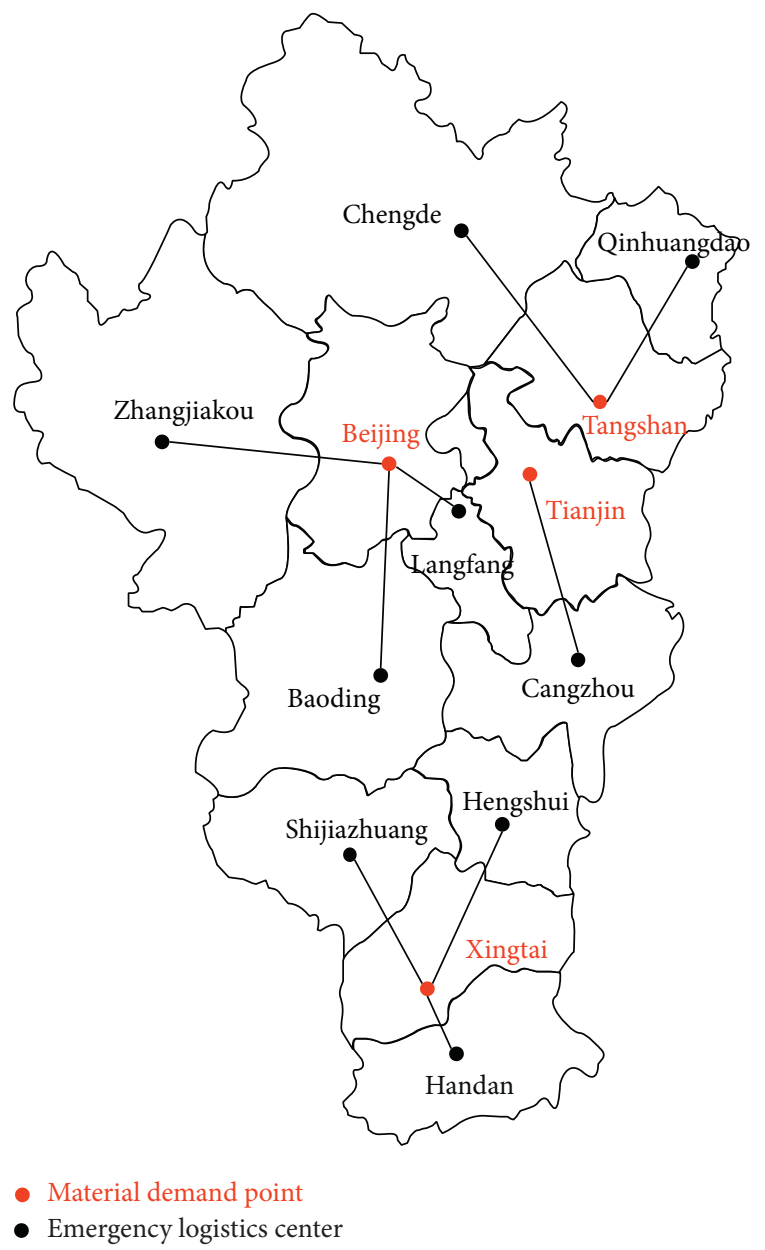

FIGURE 4: Structure of urban emergency logistics network in Beijing-Tianjin-Hebei region.

TABLE 5: Distribution of emergency materials.

\begin{tabular}{lcc}
\hline No. & City & Emergency demand point \\
\hline 1 & Beijing & Beijing, Zhangjiakou, Baoding, Langfang \\
2 & Tianjin & Tianjin, Cangzhou \\
3 & Xingtai & Xingtai, Shijiazhuang, Handan, Hengshui \\
4 & Tangshan & Tangshan, Chengde,Qinhuangdao \\
\hline
\end{tabular}

Tangshan undertake the smaller material turnover $(8.23 \%$ and 6.69\%). Emergency logistics centers 1 and 2 located in Beijing and Tianjin monopolize most of the emergency material turnover $(85.08 \%)$ in the emergency logistics network.

It can be seen from Figure 4 that four emergency logistics centers and their respective radiation material demand points form four subnetworks. Emergency logistics centers 1 and 2 in Beijing and Tianjin are in the middle of BeijingTianjin-Hebei region. Emergency logistics center 1 undertakes the emergency material supply of the most cities in all subnetworks, and Beijing, as the emergency logistics center, has the largest material demand, so it has the largest scale. The subnetwork of emergency logistics center 2 contains the fewest cities, but its scale is medium due to the large demand of materials of Tianjin; the emergency logistics center 3 of
Xingtai is located in the south of Beijing-Tianjin-Hebei region, which is responsible for the distribution of emergency materials of the same number of cities as the emergency logistics center 1, but Beijing and Tianjin, the core cities with large material demand, are located in the other two subnetworks and the total material demand of the emergency demand points in the subnetwork of Xingtai is small, so the scale of the emergency logistics center 3 is also small; the emergency logistics center 4 in Tangshan is in the north of Beijing-Tianjin-Hebei region, and the number of material demand points in the subnetwork is less than that of the emergency logistics center 3 , which contains the minimum demand of material demand points, so the scale is the smallest. In a word, it can be found that the material turnover of the emergency logistics network gathers in the central part of Beijing-Tianjin-Hebei region, and the number and relative scale of the emergency logistics centers also incline to the central part. It can be seen that the urban emergency logistics network of Beijing-Tianjin-Hebei region under major emergencies has similar nature to the urban logistics network of Beijing-Tianjin-Hebei region under normal conditions, showing an obvious core edge structure [12].

4.2. Parameter Sensitivity Analysis. From the above test results, we can see that in the final objective function, the total distance has a greater impact on the result of the objective function, while the total demand satisfaction rate has a smaller impact on the result of the objective function. Among the factors that affect the total distance, the number of emergency logistics centers plays a decisive role. If the number of emergency logistics centers is too small, each emergency logistics center is responsible for more material demand points, and the total distances between the emergency logistics centers and the corresponding material demand points are larger; when the number of emergency logistics centers is too large, the emergency logistics centers to be supplied by the material supply points are more, and the number of paths from the material supply points to the emergency logistics centers increases, so the total distance between the two will become larger. Therefore, the appropriate number of emergency logistics centers should be the Pareto optimal solution between the above two. The following is a sensitivity analysis on the number of emergency logistics centers. The number of emergency logistics centers in the model is changed, and the other parameters are unchanged. The influence of the number of emergency logistics centers on the solution of the objective function is studied so as to obtain the optimal solution of setting several emergency logistics centers in the region. The number of emergency logistics centers is set as 2, 3, 4, and 5, respectively, for testing. The test result is shown in Table 6, and the locations of emergency logistics centers are shown in Figures $5-8$. The distances between the material supply points and the emergency logistics centers, the distances between the emergency logistics centers and the material demand points, and the law of the total distance with the increase in the number of emergency logistics centers are observed, as shown in Figure 9. 
TABLE 6: Calculation results of sensitivity analysis of emergency logistics centers number.

\begin{tabular}{|c|c|c|c|c|}
\hline Number of emergency logistics centers & 2 & 3 & 4 & 5 \\
\hline $\begin{array}{l}\text { Distance between material supply points and } \\
\text { emergency logistics centers }\end{array}$ & 10.1613 & 13.8857 & 16.0276 & 18.7902 \\
\hline $\begin{array}{l}\text { Distance between emergency logistics centers } \\
\text { and material demand points }\end{array}$ & 21.3107 & 12.5024 & 10.1281 & 8.7472 \\
\hline Total distance & 31.472 & 26.3881 & 26.1557 & 27.5374 \\
\hline Emergency logistics center & $\begin{array}{l}\text { Beijing, } \\
\text { Tianjin }\end{array}$ & $\begin{array}{l}\text { Beijing, Tianjin, } \\
\text { Xingtai }\end{array}$ & $\begin{array}{l}\text { Beijing, Tianjin, } \\
\text { Xingtai, Tangshan }\end{array}$ & $\begin{array}{c}\text { Beijing, Tianjin, Handan, } \\
\text { Baoding, Tangshan }\end{array}$ \\
\hline
\end{tabular}

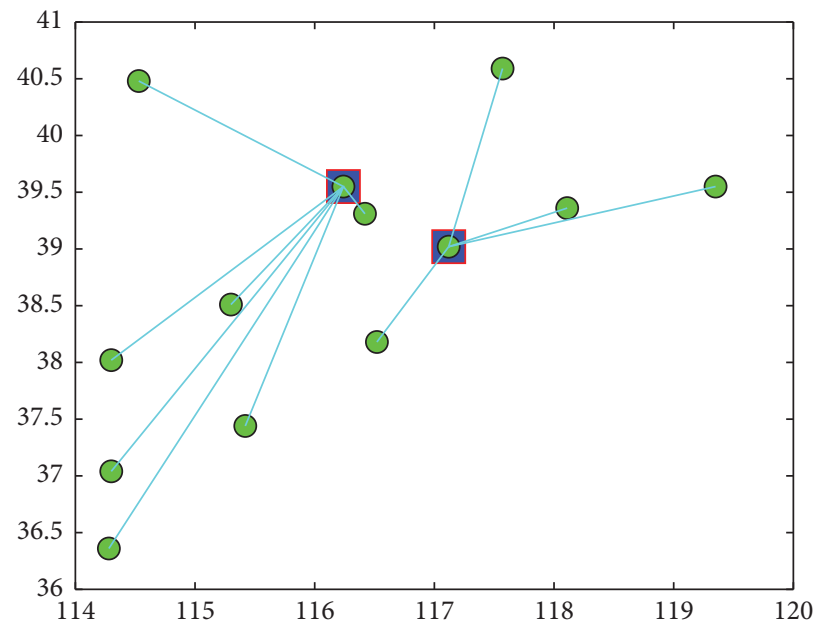

FIgURe 5: Site selection of two emergency logistics centers.

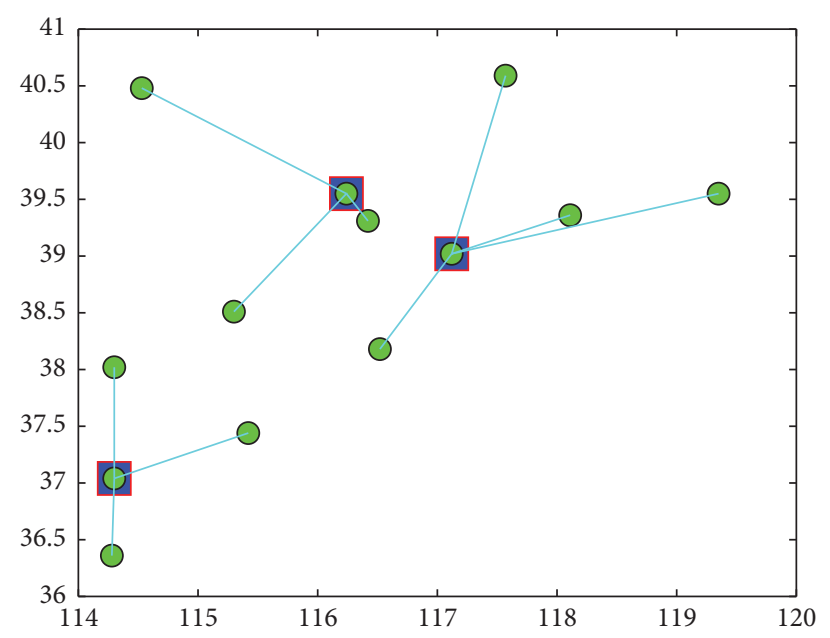

FIGURE 6: Site selection of three emergency logistics centers.

As can be seen from Table 6 and Figure 9, when the number of emergency logistics centers is increasing, the distance from the material supply points to the emergency logistics centers decreases, while the distance between the emergency logistics centers and the material demand points shows an obvious downward trend. The sum of two distances first decreases and then increases, and the minimum value is obtained when the number of emergency logistics centers is 4 , so when four emergency logistics centers are set up in Beijing-Tianjin-Hebei region, the transportation time and cost from the material supply points to the material demand points can be greatly saved, the emergency rescue time is the shortest and the demand satisfaction rate is the highest, and the objective function obtains the optimal solution. It can be seen that the number of emergency logistics centers plays a vital role in the location model of emergency logistics centers and the value of objective function, which requires decision makers to give appropriate 


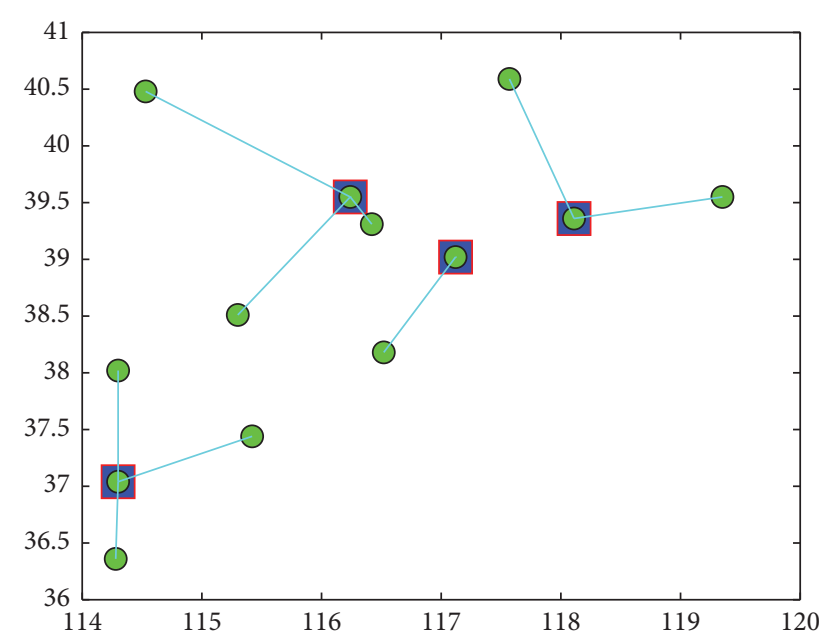

FIGURE 7: Site selection of four emergency logistics centers.

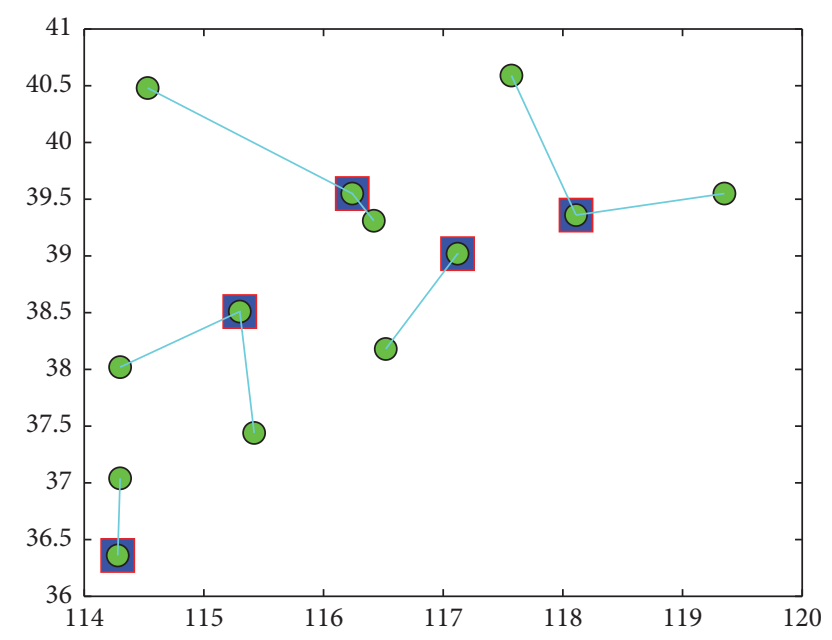

Figure 8: Site selection of five emergency logistics centers.

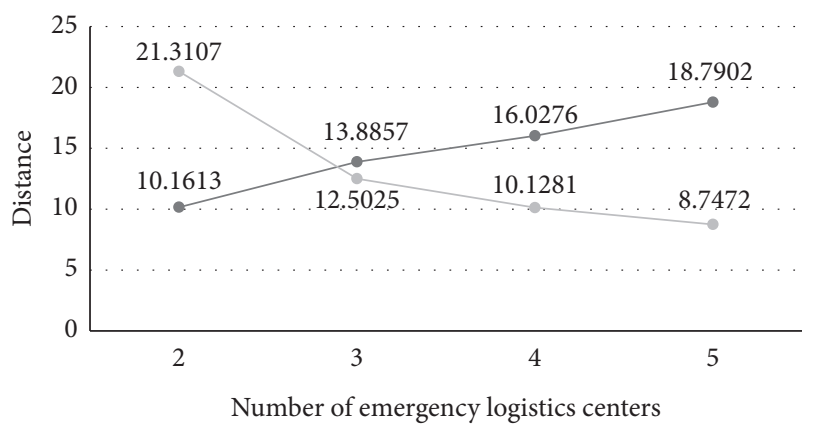

- Distance between material supply points and
emergency logistics centers
- Distance between emergency logistics centers
and material demand points

Figure 9: The trend of the distances between the three nodes in the emergency logistics network with the variation of emergency logistics centers number. value to the number of emergency logistics centers according to the actual situation when facing concrete problems so as to ensure the feasibility of the scheme, effectively reduce the emergency rescue time, and improve the demand satisfaction rate.

\section{Conclusion}

Under the background of major emergencies, the location problem of urban emergency logistics center is a complex problem with multiple objectives and constraints. In this paper, taking the shortest emergency rescue time and the highest demand satisfaction rate as the objectives, a dual objective location model of emergency logistics center is established and transformed into a single-objective model. A genetic algorithm is designed to solve the model, and an analysis of practical examples is used to verify the feasibility and effectiveness of the model and algorithm. The model has great flexibility and adaptability, and it is suitable for complex problems with multiple objectives, multiple variables, and nonlinear objective function. It is often used in programming problems, such as location-routing problem of logistics. Decision makers can adjust the parameters according to the actual situation to finish the emergency logistics center location and emergency material scheduling. In addition, this paper also considers the population density of the material demand points, the radiation radius of the emergency logistics centers, and other factors, which have important practical significance for decision makers.

The deficiency of this paper is that only a single transportation mode of emergency materials is considered. In the actual situation, there are many kinds of emergency materials and different modes of transportation. Therefore, in the next step of research, we will consider the situation of multiple materials and multimodal transportation and add them to the location model of emergency logistics center so as to select the location of emergency logistics center from a more scientific and realistic angle and improve the quality of the solution.

\section{Data Availability}

The number of permanent residents of 13 prefecture level cities in Beijing-Tianjin-Hebei region by the end of 2019 is obtained in the 2019 national economic and social development statistical communique of Beijing, Tianjin, and Hebei Province; the geographical coordinates of 13 cities of Beijing-Tianjin-Hebei region are obtained in Coordinate table of all cities in China.

\section{Conflicts of Interest}

The authors declare that they have no conflicts of interest.

\section{Acknowledgments}

This study was supported by the fund project of National Natural Science Foundation of China:"Research on 
collaborative control of urban logistics based on network theory" (61772062).

\section{References}

[1] A. Ekici, P. Keskinocak, and J. L. Swann, "Modeling influenza pandemic and planning food distribution," Manufacturing and Service Operations Management, vol. 16, no. 1, pp. 11-27, 2014.

[2] F. Barzinpour and V. Esmaeili, "A multi-objective relief chain location distribution model for urban disaster management," The International Journal of Advanced Manufacturing Technology, vol. 70, no. 5-8, pp. 1291-1302, 2014.

[3] U. R. Tuzkaya, K. B. Yilmazer, and G. Tuzkaya, "An integrated methodology for the emergency logistics centers location selection problem and its application for the Turkey case," Journal of Homeland Security \& Emergency Management, vol. 12, no. 1, pp. 121-144, 2015.

[4] M. Liu, Y. Li, J. Cao, and D. Zhang, "An optimal design of emergency logistics network for epidemic controlling based on service level," Chinese Journal of Management Science, vol. 28, no. 3, pp. 11-20, 2020, in Chinese.

[5] F. Fiedrich, F. Gehbauer, and U. Rickers, "Optimized resource allocation for emergency response after earthquake disasters," Safety Science, vol. 35, no. 1-3, pp. 41-57, 2000.

[6] W. Yi and L. Özdamar, "A dynamic logistics coordination model for evacuation and support in disaster response activities," European Journal of Operational Research, vol. 179, no. 3, pp. 1177-1193, 2007.

[7] Z. Chen and J. You, "A multi-objective decision model of emergency rescue facility location for large-scale emergency incidents," Journal of Management Science, vol. 4, pp. 10-14, 2006, in Chinese.

[8] H. Wang, L. Du, and S. Ma, "Model and algorithms for integrated open location and routing problem in emergency logistics under earthquake," Journal of Industrial Engineering and Engineering Management, vol. 30, no. 2, pp. 108-115, 2016, in Chinese.

[9] G. Chen, J. Zhang, and J. Fu, "A multi-objective locationallocation lodel for emergency logistics in an uncertain information environment," China Safety Science Journal, vol. 26, no. 12 , pp. 163-168, 2016, in Chinese.

[10] B. Zheng, Z. Ma, and Y. Zhou, "Bi-level model for dynamic location-transportation problem for post-earthquake relief distribution," Journal of Systems \& Management, vol. 26, no. 2, pp. 326-337, 2017, in Chinese.

[11] Y. Zheng, X. Huang, and Y. Pan, "Research on the multiobjective facility location model for urban emergency logistics centers," Journal of Chongqing Institute of Technology, vol. 34, no. 6, pp. 239-246, 2020, in Chinese.

[12] X. Ma and H. Wang, "Research on the structure of beijingtianjin-hebei regional logistics network-based on the perspective of social network analysis," Journal of Beijing University of Civil Engineering and Architecture, vol. 36, no. 3, pp. 95-102, 2020, in Chinese. 